\title{
Various Domains of Bond Graph
}

\author{
B. Nagalakshmi ${ }^{\mathrm{a}}$, R. Kiranmayi ${ }^{\mathrm{b}}$, and R. Nagaraju ${ }^{\mathrm{c}}$ \\ ${ }^{a}$ Asso.Prof \& Research Scholar, Dept. of EEE, KVSRIT, Kurnool, JNTUA University, Ananthapuram. \\ bProfessor \& Head, Dept. of EEE, JNTUACEA University, Ananthapuram. \\ 'Professor, Dept. of EEE St. Johns College of Eng \&Technology Kurnool (DT), AP.
}

Article History: Received: 11 January 2021; Accepted: 27 February 2021; Published online: 5 April 2021

\begin{abstract}
This paper mainly presents the purpose is to discuss the bond graph elements basics and is compared with various disciplines. Among various disciplines only electrical, mechanical, and hydraulics with examples are step by step procedure is explained and designed in bond graph model using 20 sim 4.7.

Keywords: Bond Graph, Power, Energy, Port Models, Causality and examples.
\end{abstract}

\section{Introduction}

The paper consists of a review on Bond Graph i.e. Elements, power variables, energy variables, port models, causality and comparison of various domains of Bond Graphs have been primarily used to model and predict behavior of physical systems across multiple energy domains (Nagalakshmi, 2018; Damic, 2010; Ranjeeth,2020). There is a vast literature on Bond Graph models for a wide variety of physical domains like electrical, mechanical, hydraulic systems and examples are designed in bond graph model by using 20 sim 4.7 and wave forms are obtained for some examples has been discussed (Gordana, 2017; Sampathkumar, 2020; Usha, 2020;Ranjeeth, 2019).

In human body, brain is a vital organ which acts as a central nervous system. It controls and directs the body to function properly. Since brain is an important organ, it has to be covered from harm and ailments. Few of the brain tumors are Meningioma, Glioma, and Pituitary. Firstly, Meningiomas are prominent diseases; however, it is a non-cancerous type of tumors developed in narrow walls around the brain tissues and cells (Aruna Kiruthika, 2020; Sekhar, 2020; Shankar, 2020; Latchoumi, 2013; Fu.J, 2012). Brain Tumors (BTs) are considered to be most dreadful disease which mitigates the lifetime of a human being within a short span of time. Earlier prediction of BT is highly essential and significant to extend the patient's lifespan. This is accomplished by using Magnetic Resonance Imaging (MRI) scanning model which is applied extensively by radiologists in order to examine the BT. Finally; the scan report shows whether the brain is healthy or unhealthy. Followed by, it also finds the class of tumors when it is affected by a disorder. Under the application of Machine Learning (ML), MRI reports should have a précised image for predicting BT. Initially, developer's assumed 3 portions namely, Pre-processing of MRI, Feature generation, and extraction as well as Classification.

\section{Review of 20-Sim and Bond Graph:}

20 -sim allows to create models very quickly and intuitively and supports four dynamic modeling's i.e. Iconic diagrams, Block diagrams, Bond graphs and equations build the models, simulates and analyses their performances. According to Prof Ledin from simulation and Vissim, 20-sim tool is different. It is a redevelopment of the software package simulation TUTSIM developed at the Control Laboratory (Grava, 2010).

I summarize the basic features of the bond graph methodology. .Bond Graph was introduced by Prof Henry Panter in 1959. And Prof D.Karnopp, D.Margolla, Prof R.Rosenberg elaborated the concept into methodology for physical systems modelling and can be represented in graphical (Rahim, 2018; Rahim, 2020). Bond graph is similar to block diagram or signal flow graph represents unidirectional where Bond Graphs represents bidirectional with arcs and incorporates with multiple domains. The modelling and analyzing of Bond Graphs means in a unified manner it determines the dynamics of physical systems. The instant to instant energy conservation derives by using this application. Power flows where systems are connected between them at their places are called PORTS \& MULTIPORTS are with one or more ports of the subsystems (Saeed, 2020). Each port of a system consists of four variables, namely effort e $(\mathrm{t})$, flow $\mathrm{f}(\mathrm{t}), \int \mathrm{e}(\mathrm{t}) \mathrm{dt}$ is the integral of effort which denotes $\varepsilon(\mathrm{t}) \& \int \mathrm{f}(\mathrm{t}) \mathrm{dt}$ is the integral of flow denoted as $\mathrm{F}(\mathrm{t})$.

The product of effort $e(t)$ and flow $f(t)$ variables is equal to the power ie; $p(t)=e(t) . f(t)$. Where $e(t) \& f(t)$ are called power variables. During over the period of time energy flows $\varepsilon(\mathrm{t})$ through the port and is given by $\int e(t) \cdot f(t) d t$ or $\int f(t) d \varepsilon(t) d F(t)$ or $\int e(t) d F(t)$. Where $\varepsilon(t) \& F(t)$ are called Energy Variables. Energy domain belongs a port in the system. This variables of Power and energy can be identified in various domains i.e. electrical, mechanical translation, mechanical rotation and hydraulic energy domains are listed in table (1). The physical variables are needed to model the dynamics of physical systems due to interactions described by the power variable e,f and energy variable $\varepsilon, \mathrm{F}$. 


\section{Port Models of Bond Graph:}

The dynamics of physical systems can be modelled by building complex bond graph based on component one-port, two port, and multiport elements.

A One port device has a single power port as shown in fig (1) and at this port it contains effort and flow variables in a single pair. The main components of one port are R, 1, C.

A Resistor dissipates power and thus one cannot have negative power in the port of a resistor. Capacitors and inertia (i.e. Inductor) elements store energy and release energy depending on the physical state model of the system.

The effort source (Se) and flow source (SF) are the other two important variables in one port's for the purpose of analysis. Two port devices have two ports. At every instant of time

$$
e_{1}(t) \cdot f_{1}(t)=e_{2}(t) \cdot f_{2}(t) \rightarrow(1)
$$

This equation implies that power flowing from one side of the 2-port is simultaneously flowing out of the other side (John, 2020; Anand, 2018). To satisfy the power conservation relation in a physical two port system $\mathrm{e}_{1}$ may be related to $e_{2}$ and $f_{1}$ may be related to $f_{2}$. Another possibility is $e_{1}$ may be related to $f_{2}$ and $f_{1}$ may be related to $\mathrm{e}_{2}$.A relation between the port variables that belongs to the first possibility is as follows

$$
\mathrm{e}_{1}=\mathrm{me}_{2} \quad \rightarrow(2) \text { and } \mathrm{f}_{1 \mathrm{~m}}=\mathrm{f}_{2} \rightarrow(3)
$$

These equations (1) and (2) is called transformer (TF) equations and $\mathrm{m}$ is known as the transformer modulus (Abondgraph, 2019). Ex: Gear pair, a lever, hydraulic ram etc. The second class of two port variables is

$$
\mathrm{e}_{1}=\mathrm{mf}_{2} \quad \rightarrow(4) \text { and } \mathrm{f}_{1} \mathrm{~m}=\mathrm{e}_{2} \rightarrow(5)
$$

Such equations (4), (5) are called Gyrator equations (GY) Ex: DC motor and Gyroscope.

Three ports are power conserving elements which aid in distributing power flowing into one port to two other two ports into a single power flow as shown in table (2).

The power conserving relation is written as

$$
e_{1}(t) f_{1}(t)+e_{2}(t) f_{2}(t)+e_{3}(t) f_{3}(t)=0 \rightarrow(6)
$$

Two trivial cases of three port junctions can be defined. One primitive three port has the following constitutive relations where

$$
\mathrm{e}_{1}(\mathrm{t})=\mathrm{e}_{2}(\mathrm{t})=\mathrm{e}_{3}(\mathrm{t}) \rightarrow(7) \text { and } \mathrm{f}_{1}(\mathrm{t})+\mathrm{f}_{2}(\mathrm{t})+\mathrm{f}_{3}(\mathrm{t})=0 \rightarrow(8)
$$

In equation (7) efforts are equal and where as in equation (8) sum of the flows is equal to zero and is called Common Effort Junction (0).

Another primitive three port device has the following constitutive relations where

$$
\mathrm{f}_{1}(\mathrm{t})=\mathrm{f}_{2}(\mathrm{t})=\mathrm{f}_{3}(\mathrm{t}) \rightarrow(9) \text { and } \mathrm{e}_{1}(\mathrm{t})+\mathrm{e}_{2}(\mathrm{t})+\mathrm{e}_{3}(\mathrm{t})=0 \rightarrow(10)
$$

In equation (9) flows are equal and in equation (10) sum of the efforts is equal to zero and is called Common Flow Junction (1).

\begin{tabular}{|c|l|c|c|c|}
\hline Elements & Electrical & $\begin{array}{c}\text { Mechanical } \\
\text { Translational }\end{array}$ & $\begin{array}{c}\text { Mechanical } \\
\text { Rotational }\end{array}$ & Hydraulic \\
\hline Flow (f) & Current (i) & Velocity (v) & $\begin{array}{c}\text { Angular Velocity } \\
(\mathrm{w})\end{array}$ & Volume flow (Q) \\
\hline Effort (e) & Voltage (u) & Force (f) & Porque (m) & Pressure (p) \\
\hline Power (p) & Power (u.i) & Momentum (v.f) & $\begin{array}{c}\text { Angular } \\
\text { Momentum }\end{array}$ & $\begin{array}{c}\text { Pressure } \\
\text { Momentum }\end{array}$ \\
\hline $\begin{array}{c}\text { Effort } \\
\text { Integral }\end{array}$ & Flux ( $\lambda$ ) & Displacement & Angle $(\Theta)$ & Volume (v) \\
\hline Flow Integral & Charge (q) & Mechanical work & $\begin{array}{c}\text { Mechanical } \\
\text { Work }\end{array}$ & Hydraulic energy \\
\hline Energy & Electrical energy & & &
\end{tabular}




\begin{tabular}{|c|l|c|c|c|}
\hline $\begin{array}{c}\text { Inductive } \\
\text { element }\end{array}$ & Coil & $\begin{array}{c}\text { Inertia } \\
\text { Dashpot }\end{array}$ & $\begin{array}{c}\text { Moment of inertia } \\
\text { (or) Rotary Dashpot }\end{array}$ & $\begin{array}{c}\text { Inertia of fluid } \\
\text { (or) Flow obstruction }\end{array}$ \\
\hline $\begin{array}{c}\text { Capacitive } \\
\text { element }\end{array}$ & Capacitor & Spring & Torsional Spring & $\begin{array}{l}\text { Tank } \\
\text { (or) Valve }\end{array}$ \\
\hline $\begin{array}{c}\text { Resistive } \\
\text { element }\end{array}$ & Resistance & $\begin{array}{c}\text { Friction (or) Rigid } \\
\text { bodies }\end{array}$ & Flywheels & $\begin{array}{c}\text { Friction } \\
\text { Accumulator }\end{array}$ \\
\hline Transformer & Transformer & Lever & Gears & Transducer \\
\hline Gyrator & Gyrator & ------ & Gyro & ------ \\
\hline
\end{tabular}

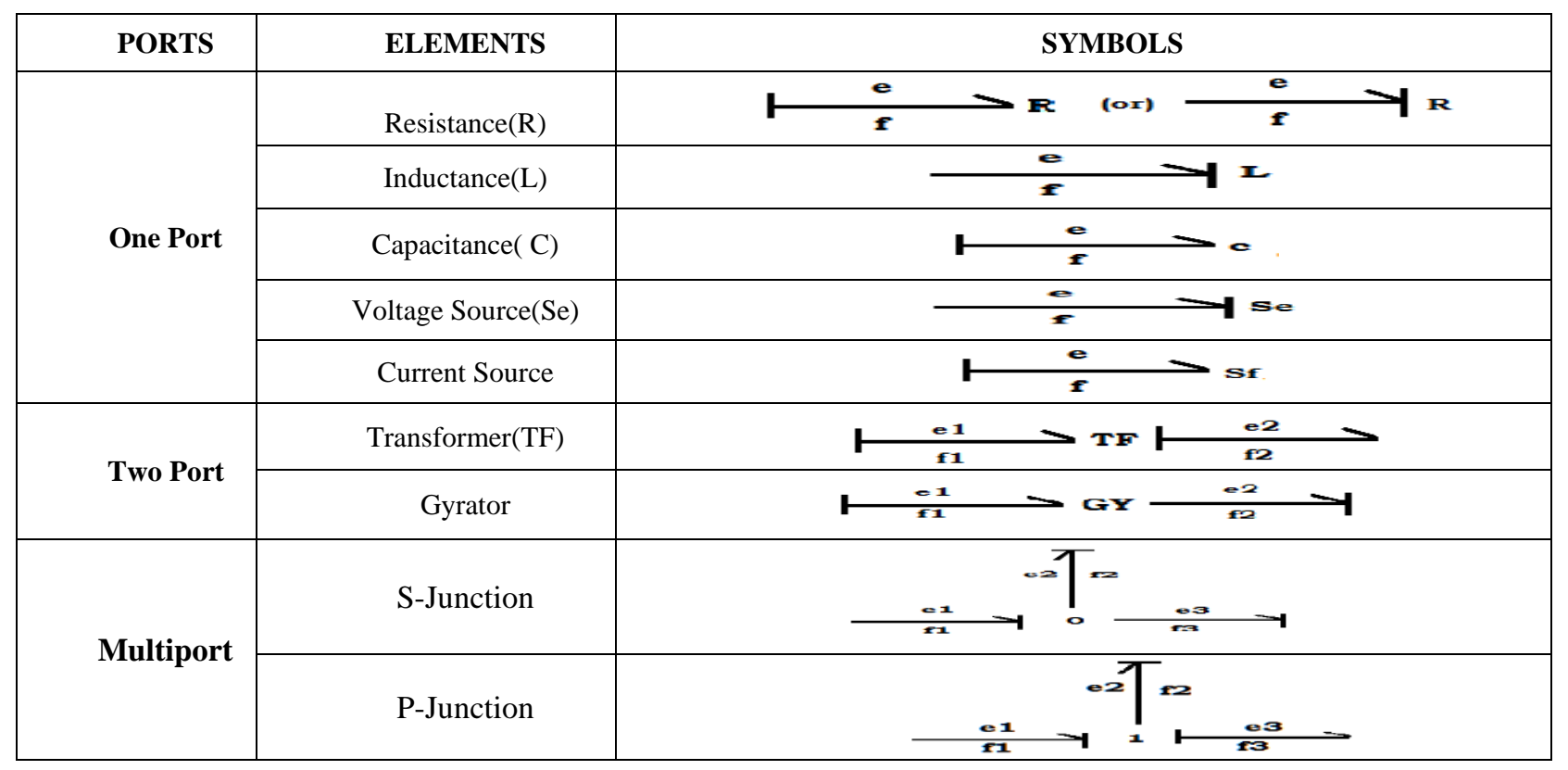

\section{Causality}

Two subsystems that are connected as shown in fig (1) through power ports i.e. share a power bond, are coupled with each other. In the fig (1) a single power bond is shown separately as an effort and a flow coupling. An effort or a flow, not both, can be an input to system A or B and the other power variable becomes the output of the system.

The effort variable from system A can be the output of system A and same will be the input to system B. The flow of system B can be the output of B and same will be the input to system A.

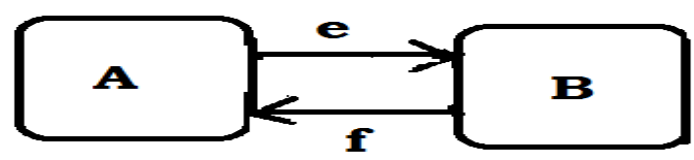

Figure 1

This relation between input effort, output flow or vice versa is called Causality in bond graph terminology. And it gives the mathematical relation between efforts and flow are used for computation. The notions of causality is used to enable computation and resolve algebraic loops when solving systems of algebraic or differential equations. This notion of causality is extended to one port, two port and three port component models.

A Resistor can be represented by two equivalent relations, namely e $=\Phi$ (f) or $f=\Phi^{-1}(e)$, where the convention is that the variable on the left of the equality sign represents the output (dependent variable) and that on the left is the input (independent variable).

Now consider a capacitor with constitutive equations which are equivalent namely $\mathrm{e}=\Phi^{-1}\left(\int \mathrm{f}(\mathrm{t})\right)$ or $\mathrm{f}=\mathrm{d} / \mathrm{dt}[\Phi(\mathrm{e})]$

The first equation denotes integral causality and the second derivative causality. 


\section{Design Model Examples}

Example 5.1: Construction steps of a bond graph of a simple electrical circuit:

A simple electrical circuit is used to demonstrate the step by step procedure to construct its bond graph for fig (2).

1. Recognize the elements of the electrical system i.e. R, L, C and Sources.

2. Place all of the nodes with 0 -junctions as shown in fig (2a).

3. All the elements of 1 -junctions are added acting at their own 1-junctions. And if there is any ground terminal is their pick up the ground terminal. The ground terminal is simply a 0 -junction and assume it has no voltage. (In this example no ground terminal is taken).

4. And drawn arrows for the bonds and it must be towards ground as shown in fig (2a). 5. Removing all 0junctions or 1-junctions less than three bonds and finally in fig ( $2 \mathrm{~b})$ a modified simple bond graph model is shown.

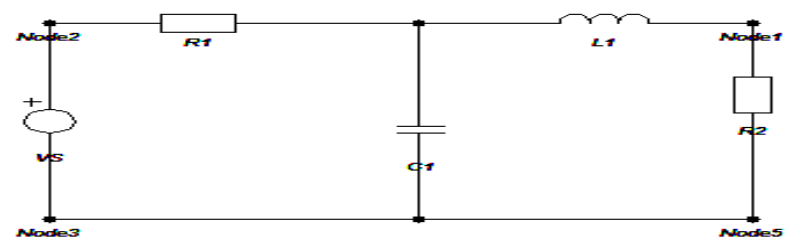

Figure 2 Electrical circuit

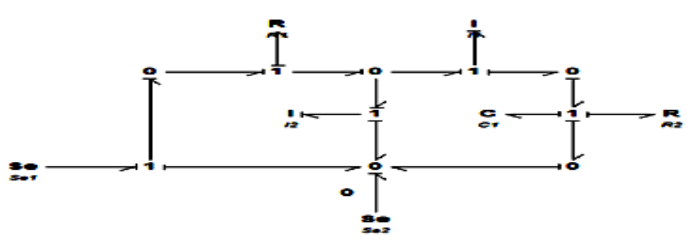

Figure 2 (a) Bond Graph model

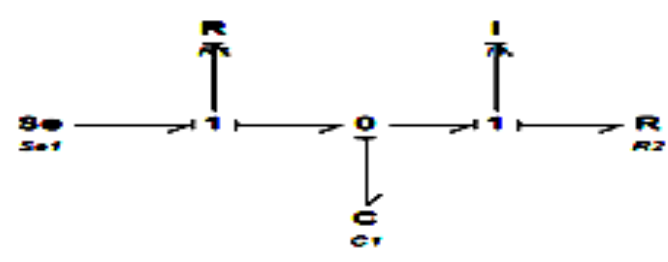

Figure 2 (b) Simplified Bond Graph model

Example 5.2: For fig (3) the same construction steps are to be followed for example (2) of electrical system. The fig (3a) represents the building of bond graph model with bonds and causality and fig (3b) shows its modified bond graph model.

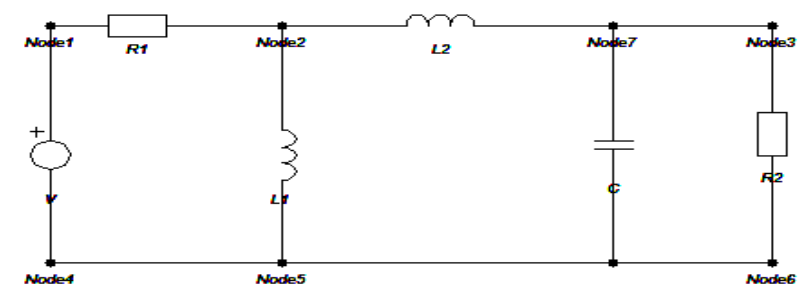

Figure 3 Electrical circuit 


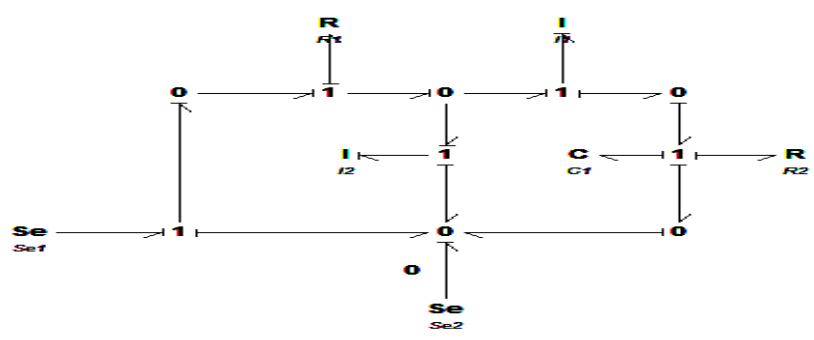

Figure 3 (a) Bond Graph Model with Causality

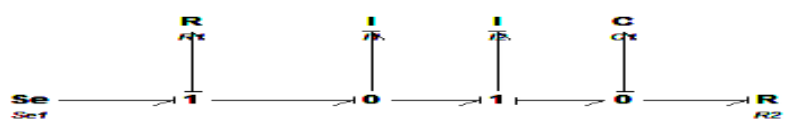

Figure 3 (b) Simplified Bond Graph Model

Example 5.3: Bond Graph Construction steps for Mechanical system:

1. In mechanical system also we have to Identify the elements i.e., mass (I), spring constant(C), damper (R), sources (se or sf) etc. for the given fig (4).

2. Each distinct velocity is placed with 1 -junctions (usually at a mass) and inserted with their sources and $\mathrm{L}$ bonds where they act on the 1 -junctions.

3. Power flow directions are assigned with bonds and causality as shown in fig (4a).

4. From 0 and 1 junctions less than three bonds are removed and its simplified bond graph is shown in fig (4b).

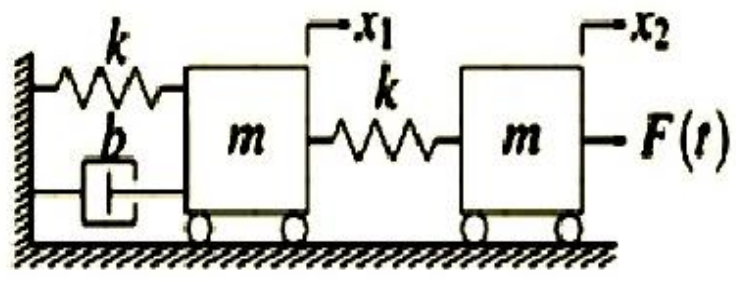

Figure 4 Mechanical System

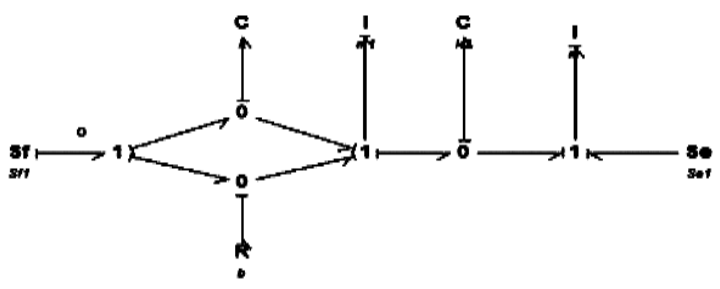

Figure 4 (a) Bond Graph Model

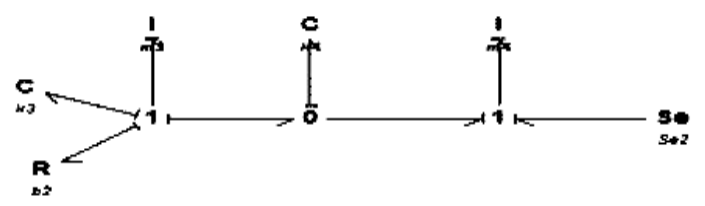

Figure 4 (b) Simplified Bond Graph Model

Example 5.4: The same construction steps are followed for example (2) of mechanical system as discussed in example (3). In this example lever (i.e. transformer) MSF and wave generator is used. The fig (5) consists of the following parameters with values spring constant $(\mathrm{c})=100 \mathrm{MF}, \mathrm{TF}=\operatorname{adverb} 3$, mass $(\mathrm{I})=10$, sine wave amplitude $=100$.

Fig (5) shows the simple mechanical system and its simplified modified bond graph model is shown in fig (5a).The output characteristics is shown in fig (5b). Where sine waveform represents across flow and time (i.e. Green). Where the other one represents across spring deflection and time (i.e. black). 


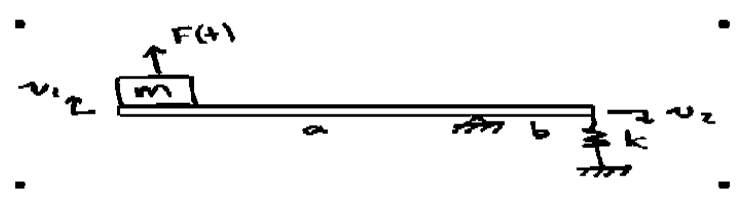

Figure 5 Mechanical System

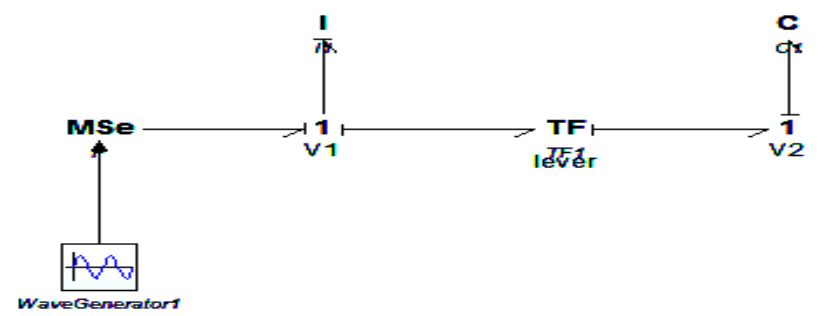

Figure 5 (a) Simplified Bond Graph Model

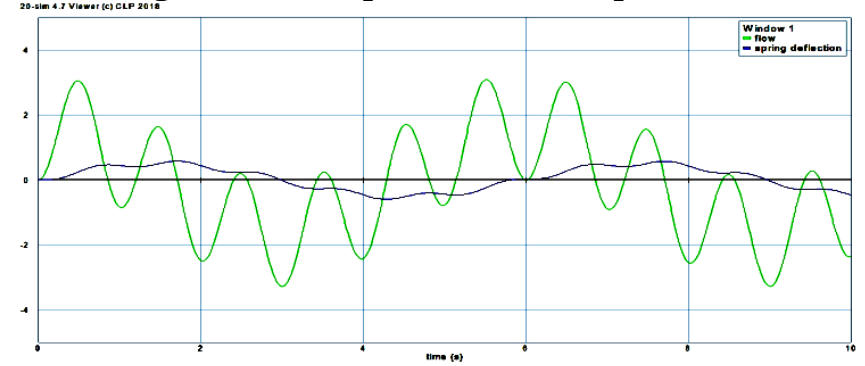

Figure 5 (b) Waveform

Example 5.5: Construction steps of a Bond Graph for Hydraulic System shown in fig (6)

1. In Hydraulic system first recognize the elements i.e. Inertias (I), Tanks (c), Valves (v).The element that stores kinetic energy is the Inertia (I).The element that stores potential energy is the Tank(c) and the elements which dissipates energy is the $\operatorname{Valve}(\mathrm{R})$.

2. The next step is to draw 0 -junctions at all the nodes

3. Now distinct volume flow rates represents 1 junction and the physical elements are connected which experiences their relative volume flow rates i.e. I, R, C, Sources and Sinks etc., with bonds.

4. Less than three bonds of the junctions is removed and at last a modified simple bond graph model is obtained as shown in fig (6a) and its output waveform is shown in fig (6b).

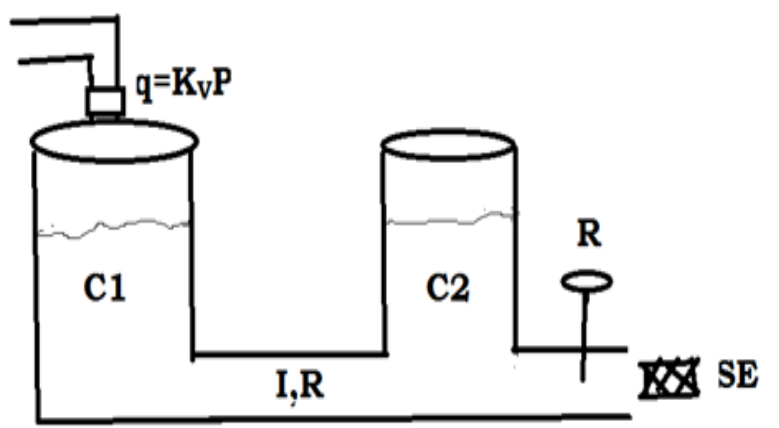

Figure 6 Hydraulic System 


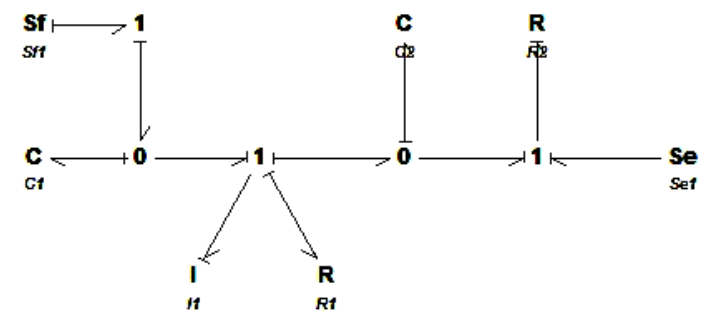

Figure 6 (a) Simplified Bond Graph Model

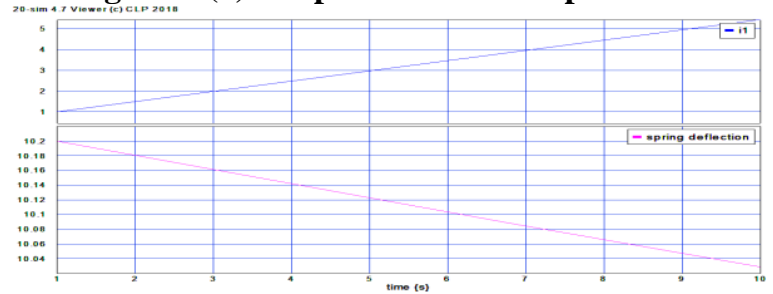

Figure 6 (b) Waveform

Example 5.6: As discussed for example (5) the construction steps of Hydraulic system are same and follows the same steps for example (6).

The simple Hydraulic system shows fig (7) and fig (7a) shows its bond graph model modified.

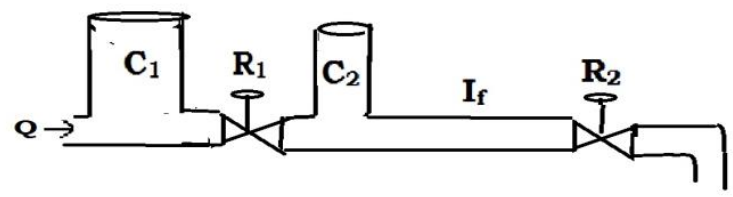

Figure. 7 Hydraulic System

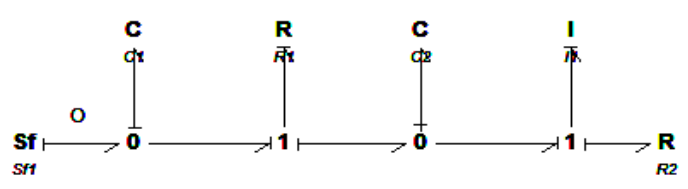

Figure. 7 (a) Simplified Bond Graph Model

\section{Conclusion}

An overview of Bond Graph with power bonds, energy port models causality is implemented in this paper. The elements of various domains is compared like Electrical, Mechanical and Hydraulic. Two examples of Electrical Mechanical and Hydraulic are taken and designed in a simplified Bond Graph by using 20 Sim 4.7 and better output results are obtained for some examples. This paper may be helpful for my further research work.

\section{Acknowledgment}

As a researcher to be a part of the Electrical world, I am very happy. The authors and well-wishers those who supported this paper to write and for their cooperation for discussions and contribution thanks to all. This Paper gives the idea to extent the review paper participating in its early stage. A warm wish to my husband who supported me to complete this paper.

\section{References}

1. Abondgraph approach Gilberto Gonzalez-A, Neo Bareera-G, Geratdo Ayala Dynamic performance of a sky stream wind turbine: -Article:1709361, https://www.tandfonline.com/doi/full/10.100/2331 1916.2019.1709361. 10.https://en.m.wikipedia.org 20-sim / Modeling and simulation. 
2. Anand Vaz, Prof, Dept of Mechanical Engg., Dr. B.R.Ambedekar National Institution of Technology Jalandhar Punjab 144011, India. 'Introduction to Physical Systems, their modeling simulation. A Bond Graph approach'

3. Damic, V (Jekoslav); Cohodar, M (Aida) and Kulenovic. M (Alik) 23(1) ISSN 2304 - 1382, 2012. 'Modeling and Simulation of Hydraulic Systems by Bond Graph'

4. Gordana Janevska.(2017) 'Bond Graph approach to modeling thermal process article' in IJSER 8 (5): $736-740$.

5. GRAVA Adriana, GRAVA Cristian, NOVAC Mihaela, PANTEA Mircea University of Oradea, Faculty of Electrical Engineering and Information Technology 1, University Str., 410087

6. 'Bond-graph Methods for Electric Circuits Analysis'

7. Latchoumi, T. P., Loganathan, J., Parthiban, L., \& Janakiraman, S. (2016, August). OFS method for selecting active features using clustering techniques. In Proceedings of the International Conference on Informatics and Analytics (pp. 1-4).

8. Latchoumi, T. P., \& Parthiban, L. (2016). Secure Data Storage in Cloud Environment using MAS. Indian Journal of Science and Technology, 9, 24-29.

9. Latchoumi, T. P., \& Kannan, V. V. (2013). Synthetic Identity of Crime Detection. International Journal, 3(7), 124-129.

10. Latchoumi, T. P., Kannan, V. V., \& Ezhilarasi, T. P. (2013). Leasing Processing Power from Mid network using Wireless Communication. International Journal, 3(5), 191-199.

11. Nagalakshmi .B M.Tech (ph.d), Dr R.Kiranmayi prof and Head, Dr K.Nagaraju prof.(2018) 'A Brief review on Bond Graph'118(14), 675 - 681 ISSN: 1311 - 8080 Url: http://www.ijpam.eu.

12. .Rahim, R., Murugan, S., Priya, S., Magesh, S., \& Manikandan, R. Taylor Based Grey Wolf Optimization Algorithm (TGWOA) For Energy Aware Secure Routing Protocol.

13. Rahim, Robbi, S. Murugan, Reham R. Mostafa, Anil Kumar Dubey, R. Regin, Vikram Kulkarni, and K. S. Dhanalakshmi. (2020) "Detecting the Phishing Attack Using Collaborative Approach and Secure Login through Dynamic Virtual Passwords." Webology 17(2).

14. Ranjeeth, S., Latchoumi, T. P., Sivaram, M., Jayanthiladevi, A., \& Kumar, T. S. (2019, December). Predicting Student Performance with ANNQ3H: A Case Study in Secondary Education. In 2019 International Conference on Computational Intelligence and Knowledge Economy (ICCIKE) (pp. 603607). IEEE.

15. Ranjeeth, S., \& Latchoumi, T. P. (2020),Predicting Kids Malnutrition Using Multilayer Perceptron with Stochastic Gradient Descent, 34(5), Revue d'Intelligence Artificielle, 631-636

16. Saeed Karimain,ZAHRA Jahanbin Meccanica, (2020) Bond graph modeling of a typical flapping wing micro-air-vehicle with the elastic articulated wings 55,1263-1294 https://link.springer.com/article/10.1007/s11012-020-01162-w.

17. Sampathkumar, A., R. Maheswar, Pon Harshavardhanan, S. Murugan, P. Jayarajan, and V. Sivasankaran. (2020) "Majority Voting based Hybrid Ensemble Classification Approach for Predicting Parking Availability in Smart City based on IoT." In 2020 11th International Conference on Computing, Communication and Networking Technologies (ICCCNT), pp. 1-8.

18. Sekaran, K., Rajakumar, R., Dinesh, K., Rajkumar, Y., Latchoumi, T. P., Kadry, S., \& Lim, S. (2020). An energy-efficient cluster head selection in wireless sensor network using grey wolf optimization algorithm. TELKOMNIKA, 18(6), 2822-2833.

19. Shankar, G., Latchoumi, T. P., Chithambarathanu, M., Balayesu, N., \& Shanmugapriya, C. (2020). An Efficient Survey on Energy Conservation System with Video Surveillance. Journal of Xian University of Architecture and Technology, 12(7), 100-106.

20. Usha Kiruthika,Thamarai Selvi Somasundaram, S. Kanaga Suba Raja, (2020) 'Lifecycle Model of a Negotiation Agent: A Survey of Automated Negotiation Techniques', Group Decision and Negotiation, ISSN 0926-2644, 29(6), pp. 1239-1262. https://doi.org/10.1007/s10726-020-09704-z (IF: 1.612)

21. Wolfgang Borutely. Bond Graph Methodology, Development and of Multidisciplinary Dynamic system model 